\title{
Cost-effectiveness of routine screening for Lynch syndrome in colorectal cancer patients up to 70 years of age
}

\author{
Celine H.M. Leenen, MD, PhD', Anne Goverde, MD ${ }^{1,2}$, Esther W. de Bekker-Grob, PhD, \\ Anja Wagner, MD, PhD², Margot G.F. van Lier, MD, PhD', Manon C.W. Spaander, MD, PhD1, \\ Marco J. Bruno, MD, PhD ${ }^{1}$, Carli M. Tops, $\mathrm{PhD}^{4}$, Ans M.W. van den Ouweland, $\mathrm{PhD}^{2}$, \\ Hendrikus J.Dubbink, PhD ${ }^{5}$, Ernst J. Kuipers, MD, PhD ${ }^{1,6}$, Winand N.M. Dinjens, $\mathrm{PhD}^{5}$, \\ Monique E. van Leerdam, MD, $\mathrm{PhD}^{1,7}$ and Ewout W. Steyerberg, $\mathrm{PhD}^{3}$; on behalf of the LIMO study group
}

Purpose: To assess the cost-effectiveness of routine Lynch syndrome (LS) screening among colorectal cancer (CRC) patients $\leq 70$ years of age.

Methods: A population-based series of CRC patients $\leq 70$ years of age was routinely screened for LS. We calculated life years gained (LYG) and incremental cost-effectiveness ratios (ICERs) for different age cutoffs and comparing age-targeted screening with the revised Bethesda guidelines.

Results: Screening 1,117 CRC patients identified 23 LS patients, of whom 7 were $\leq 50$ years of age, 7 were $51-60$, and 9 were $61-70$. Additionally, 70 LS carriers were identified among relatives (14, 42, and 14 per age category). Screening amounted to 205.9 LYG or 43.6, 118.0, and 44.3 LYG per age category. ICERs were $€ 4.226 / \mathrm{LYG}$ for screening CRC patients $\leq 60$ years of age compared with those $\leq 50$ years and $€ 7.051 / L Y G$ for screening CRC patients $\leq 70$ years compared with those $\leq 60$ years. The revised Bethesda guidelines identified 70 of 93 (75\%) LS carriers. The ICER for LS screening in CRC patients $\leq 70$ years of age compared with the revised Bethesda guidelines was $€ 7.341 / L Y G$. All ICERs remained less than $€ 13.000 / L Y G$ in one-way sensitivity analyses.

Conclusion: Routine LS screening by analysis of microsatellite instability, immunohistochemistry, and $M L H 1$ hypermethylation in CRC patients $\leq 70$ years of age is a cost-effective strategy with important clinical benefits for CRC patients and their relatives.

Genet Med advance online publication 3 March 2016

Key Words: gastrointestinal oncology; hereditary; molecular diagnostics

\section{INTRODUCTION}

Lynch syndrome (LS) is the most common hereditary colorectal cancer (CRC) syndrome, responsible for $2-3 \%$ of all CRC cases. ${ }^{1-3}$ This syndrome is characterized by early onset of CRC, endometrial cancer, and other extracolonic cancers. ${ }^{4}$ Mutations in one of the four mismatch repair (MMR) genes MLH1, MSH2, MSH6, and PMS2 or the TACSTD1 gene are the underlying defect in LS. ${ }^{5}$ Detection of LS in CRC patients is of great importance because affected patients and family members can benefit from LS surveillance programs, which reduce CRC incidence and mortality by $56-70 \% .6,7$

Molecular diagnostics on tumor tissue consisting of analysis for microsatellite instability (MSI) and immunohistochemical staining (IHC) for loss of MMR protein expression can identify patients at high risk for LS. ${ }^{8,9}$ However, loss of MLH1 protein expression can also occur in sporadic tumors as a result of somatic MLH1 promoter hypermethylation. Therefore, sporadic MLH1-deficient tumors can be distinguished from LS-associated tumors by $M L H 1$ hypermethylation analysis. ${ }^{9}$

The revised Bethesda guidelines have been developed to select patients eligible for MSI testing and IHC analysis based on clinical criteria. ${ }^{10}$ These guidelines are poorly applied in clinical practice and may miss a substantial number of LS patients because of limited sensitivity. ${ }^{11}$ Routine analysis of MSI and IHC was previously recommended in CRC patients $<50$ years of age. ${ }^{12}$ This strategy predominantly fails to identify MSH6 and PMS2 mutation carriers because the mean age of CRC diagnosis in these subjects is $>50$ years. ${ }^{13,14}$ Routine screening for LS has been proposed to improve LS detection, but age cutoffs are still under debate. ${ }^{15-17}$ Recently, the US Multi-Society Task Force on Colorectal Cancer as well as a European group of experts recommended routine LS screening via analysis of MSI

The first two authors contributed equally to this work

${ }^{1}$ Department of Gastroenterology and Hepatology, Erasmus MC, University Medical Center, Rotterdam, The Netherlands; ${ }^{2}$ Department of Clinical Genetics, Erasmus MC, University Medical Center, Rotterdam, The Netherlands; ${ }^{3}$ Department of Public Health, Erasmus MC, University Medical Center, Rotterdam, The Netherlands; ${ }^{4}$ Department of Clinical Genetics, Leiden University Medical Center, Leiden, The Netherlands; ${ }^{5}$ Department of Pathology, Erasmus MC, University Medical Center, Rotterdam, The Netherlands; ${ }^{6}$ Department of Internal Medicine, Erasmus MC, University Medical Center, Rotterdam, The Netherlands. ${ }^{7}$ Current address: Department of Gastroenterology and Hepatology, Antoni van Leeuwenhoek Hospital, Netherlands Cancer Institute, Amsterdam, The Netherlands. Correspondence: Celine Leenen (c.leenen@vumc.nl) 
or IHC and MLH1 hypermethylation in CRC patients. ${ }^{18,19}$ The US guidelines support universal tumor testing for LS, whereas European experts recently recommended universal LS screening or routine screening of CRC patients up to 70 years of age.

We previously reported that routine analysis of MSI and IHC for MMR proteins revealed a profile compatible with LS in $4.5 \%$ of CRC patients $\leq 70$ years of age..$^{20}$ Many of these patients were $>50$ years of age. ${ }^{20}$ The current study aimed to assess the cost-effectiveness of routine screening for LS by analysis of MSI, IHC, and $M L H 1$ hypermethylation in CRC patients $\leq 70$ years of age. We compared costs and health benefits for age-targeted LS screening up to 70 years of age. Also, we compared routine LS screening among CRC patients up to age 70 with LS screening based on the revised Bethesda guidelines.

\section{MATERIALS AND METHODS}

\section{Subjects and diagnostic workup}

The present study is an extension of a prospective populationbased study on the yield of routine molecular screening for LS in CRC patients up to 70 years of age. ${ }^{20}$ Consecutive CRC patients $\leq 70$ years of age $(n=1,117)$ from 11 Dutch hospitals between May 2007 and September 2009 were included. The diagnostic approach and methods regarding tumor analyses and germ-line mutation analyses have been described in detail elsewhere. ${ }^{20}$ In summary, MSI analysis and IHC for MLH1, MSH2, MSH6, and PMS2 protein expression were performed in tumor tissue of CRC patients $\leq 70$ years of age. $M L H 1$ hypermethylation analysis was performed in cases with loss of MLH1 protein expression. BRAF mutation analysis was not included in this cost study because previous studies have shown that $M L H 1$ promoter hypermethylation analysis is superior to $B R A F$ mutation analysis as a prescreening method. ${ }^{21}$ If tumors showed a high degree of MSI and/or absence of MMR protein without MLH1 promoter hypermethylation, then patients were suspected of having LS. These patients were offered genetic counseling and germ-line mutation analysis (Figure 1). If patients suspected of having LS had died before they could be referred to a clinical geneticist, then genetic counseling was offered to their first-degree relatives. In the Netherlands, costs of genetic counseling and germ-line mutation analysis are covered by the mandatory basic health insurance.

If a pathogenic germ-line mutation was identified in one of the MMR genes or the TACSTD1 gene, then patients were labeled index patients. Relatives were contacted by index patients and were offered genetic counseling and targeted mutation analysis. We collected data on the number of relatives accepting counseling and targeted mutation analysis and the number of LS carriers identified among these relatives until May 2014. This study was approved by the institutional review boards of the participating hospitals.

\section{Effectiveness}

Effectiveness of LS screening was expressed in life years gained (LYG), based on the number of LS carriers detected among CRC patients and their relatives and using estimations from literature. In previous studies, LS surveillance was associated with 0.09-2.5 LYG for index patients and 0.49-32.69 LYG for relatives. ${ }^{12,16,17,22-29}$ For our analysis, we took the reported 3\% discounted LYG directly from previous studies. If only undiscounted LYG or LYG with a different discount rate was reported, then we discounted them by 3\% annually (Supplementary Table S1 online). If adherence to LS surveillance programs was not included in the reported LYG, then we corrected the LYG by assuming adherence to these programs of $80 \%$ for both index patients and LS carriers among their relatives. ${ }^{16}$ We used the median of all estimations from the literature in our base case scenario (Table 1). If the index patient had died, then only relatives were considered to benefit from surveillance. For CRC patients and relatives with no pathogenic mutation identified, we assumed no surveillance costs or benefits.

\section{Costs}

Direct medical costs of all analyses in the diagnostic workup were determined following the microcosting method, which is based on comprehensive bottom-up analyses. ${ }^{30}$ Cost data included costs of employment, material, equipment, and overhead, which were obtained from the Department of Pathology and the Department of Clinical Genetics of the Erasmus MC, University Medical Center Rotterdam (Supplementary Table S2 online). Costs of PMS2 germ-line mutation analysis were assumed to be similar to costs of germ-line mutation analysis of other MMR genes. Total costs were calculated based on the number of CRC patients and relatives analyzed. The costs of MMR gene sequencing in index patients were calculated using the total number of genes analyzed. LS surveillance costs for index patients and relatives were estimated from previous literature, including costs of colonoscopy, transvaginal ultrasonography, and endometrial biopsy (Table 1 and Supplementary Table S2 online). ${ }^{16,31}$ Costs of gynecological screening were available only in dollars and were converted to Euros using purchasing-power parity. All costs were converted to the price level of 2013 using the Dutch consumer price index. ${ }^{32}$ Surveillance by colonoscopy with polypectomy every 2 years was assumed to start at the age of LS diagnosis or at age 25 for relatives younger than 25 years of age. LS surveillance was assumed to be continued until 75 years of age. For cost savings by prevention of CRC in surveillance programs, the most conservative estimate, i.e., only treatment costs for the first 12 months of stage I CRC, was used (Supplementary Table S2 online). Female LS carriers were assumed to receive yearly gynecological surveillance by transvaginal ultrasonography and endometrial biopsy starting at age 35 and continuing until prophylactic surgery at 40 years of age, after childbearing was completed. Prophylactic surgery (total abdominal hysterectomy and bilateral salpingo-oophorectomy) was assumed to be accepted by $19 \%$ of the index patients and $18 \%$ of their relatives. ${ }^{16}$ LS carriers not accepting prophylactic surgery were assumed to continue yearly gynecological surveillance up to 75 years of age. All costs were discounted by $3 \%$ annually. 


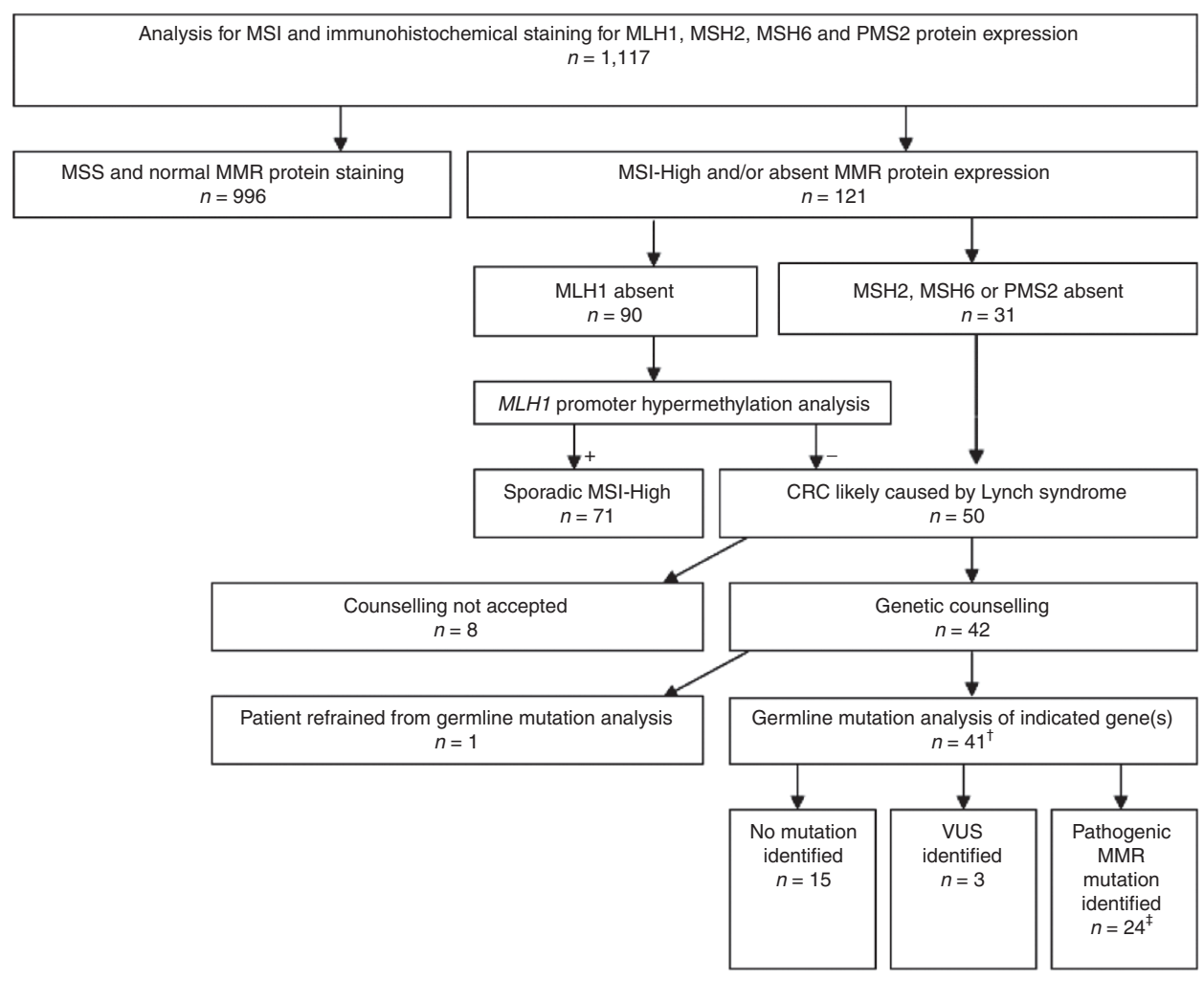

Figure 1 Diagnostic workup to detect Lynch syndrome among colorectal cancer patients $\leq \mathbf{7 0}$ years. CRC, colorectal cancer; MMR, mismatch repair; MSI, microsatellite instability; MSI-High, high degree of MSI; MSS, microsatellite stable; VUS, variant of unknown significance. ${ }^{\dagger}$ In 4 of 41 cases, germ-line mutation analysis was performed in a first-degree relative. ${ }^{\ddagger}$ In one patient, a pathogenic MMR mutation was identified in stromal tissue resected during colorectal cancer surgery. Neither this patient nor any relatives were available for germ-line mutation analysis. This patient was excluded from the analyses.

\section{Cost-effectiveness analyses}

We evaluated cost-effectiveness of LS screening using a base-case cost-effectiveness model (i.e., using the most plausible parameter values), and age cutoffs of 60 and 70 years from a health-care-provider perspective. LS screening was the reference strategy for CRC patients $\leq 50$ years of age. Incremental cost-effectiveness ratios (ICERs) per age cutoff were expressed as additional costs per LYG. To test the robustness of ICERs, we performed one-way sensitivity analyses. Costs were assumed to range from half as much to twice as much as calculated. Ranges for all other parameters were based on literature (Table 1).

\section{Fulfillment of the revised Bethesda guidelines}

The proportion of CRC patients fulfilling the revised Bethesda guidelines was based on the literature (Table 1). In an unselected population, $26-50 \%$ of CRC patients fulfill the revised Bethesda guidelines. ${ }^{1,3,33}$ We assumed only $26 \%$ of the CRC patients in our cohort fulfilled these guidelines, because this approach is unfavorable for an age-targeted screening strategy. For all index patients, a detailed family history was obtained during genetic counseling and fulfillment of the revised Bethesda guidelines was assessed by one clinical geneticist (A.W.).

\section{RESULTS}

In our population-based cohort, 50 of 1,117 CRC patients (4.5\%) were suspected of having LS by routine analysis of MSI and IHC (Figure 1). Consecutive MMR gene sequencing in 42 of these CRC patients finally identified 24 LS patients (2.1\%). In one case, the germ-line mutation was identified in stromal tissue resected along with the CRC tissue. Because neither this patient nor any relatives were available for MMR gene sequencing, the patient was not considered an index patient.

\section{Effectiveness of age-targeted strategies}

The median age of CRC patients was 61 years (interquartile range: 55-66); 144 CRC patients were $\leq 50$ years of age, 377 CRC patients were 51-60 years, and 596 CRC patients were 61-70 years. The prevalence of LS decreased from $4.9 \%(7 / 144)$ in the age category $\leq 50$ years to $2.1 \%(8 / 377)$ in CRC patients $51-60$ years and $1.5 \%$ (9/596) in CRC patients 61-70 years (Table 2).

For index patients $\leq 50$ years of age, a total of 29 first-degree relatives were eligible for targeted mutation analysis compared with 44 and 40 first-degree relatives in the age categories 51-60 years and 61-70 years, respectively. Genetic counseling and targeted mutation analysis were offered to these relatives and cascaded to further relatives if indicated. For each index, 
Table 1 Parameters and values used in the cost-effectiveness analysis

\begin{tabular}{|c|c|c|c|}
\hline Parameter & Base case value & Range & Source \\
\hline \multicolumn{4}{|l|}{ Median age at LS diagnosis } \\
\hline Index patients & 57 & IQR 49-63 & 20 \\
\hline Relatives & 41 & IQR 32-56 & Current study \\
\hline Female index patients & 61 & IQR 53-66 & Current study \\
\hline Female relatives & 38 & IQR 29-56 & Current study \\
\hline \multicolumn{4}{|l|}{ LS surveillance } \\
\hline \multicolumn{4}{|l|}{ Discounted life years gained ${ }^{a}$} \\
\hline Female index patients & 0.66 & $0.191-2.15$ & $12,16,23,24,26,27$ \\
\hline Male index patients & 0.66 & $0.092-2.15$ & $12,16,23,24,26,27$ \\
\hline Female relatives & 2.83 & $0.40-16.02$ & $12,16,17,22-29$ \\
\hline Male relatives & 2.83 & $0.47-16.47$ & $12,16,17,22-29$ \\
\hline Interval between colonoscopies (years) & 2 & $1-2$ & 18,19 \\
\hline Complication rate of colonoscopy & 0.0024 & - & 31 \\
\hline \multicolumn{4}{|l|}{ Acceptance of prophylactic gynecological surgery } \\
\hline Index patients & 0.19 & $0.10-0.30$ & 16 \\
\hline Relatives & 0.18 & $0.03-0.25$ & 16 \\
\hline \multicolumn{4}{|l|}{ CRC risk and risk reduction } \\
\hline Lifetime risk of developing CRC for $L S$ carriers & 0.25 & $0.25-0.70$ & $6,7,28,46$ \\
\hline Reduction in CRC risk by LS surveillance & 0.56 & $0.56-0.70$ & 6,7 \\
\hline \multicolumn{4}{|l|}{ Revised Bethesda guidelines } \\
\hline $\begin{array}{l}\text { Proportion of CRC patients fulfilling the revised Bethesda guidelines in } \\
\text { an unselected CRC population }\end{array}$ & 0.26 & $0.26-0.50$ & 1,47 \\
\hline
\end{tabular}

CRC, colorectal cancer; IQR, interquartile range; LS, Lynch syndrome.

a Life years gained were discounted by $3 \%$ annually.

Table 2 Number of patients screened and detection of Lynch syndrome among CRC patients and relatives

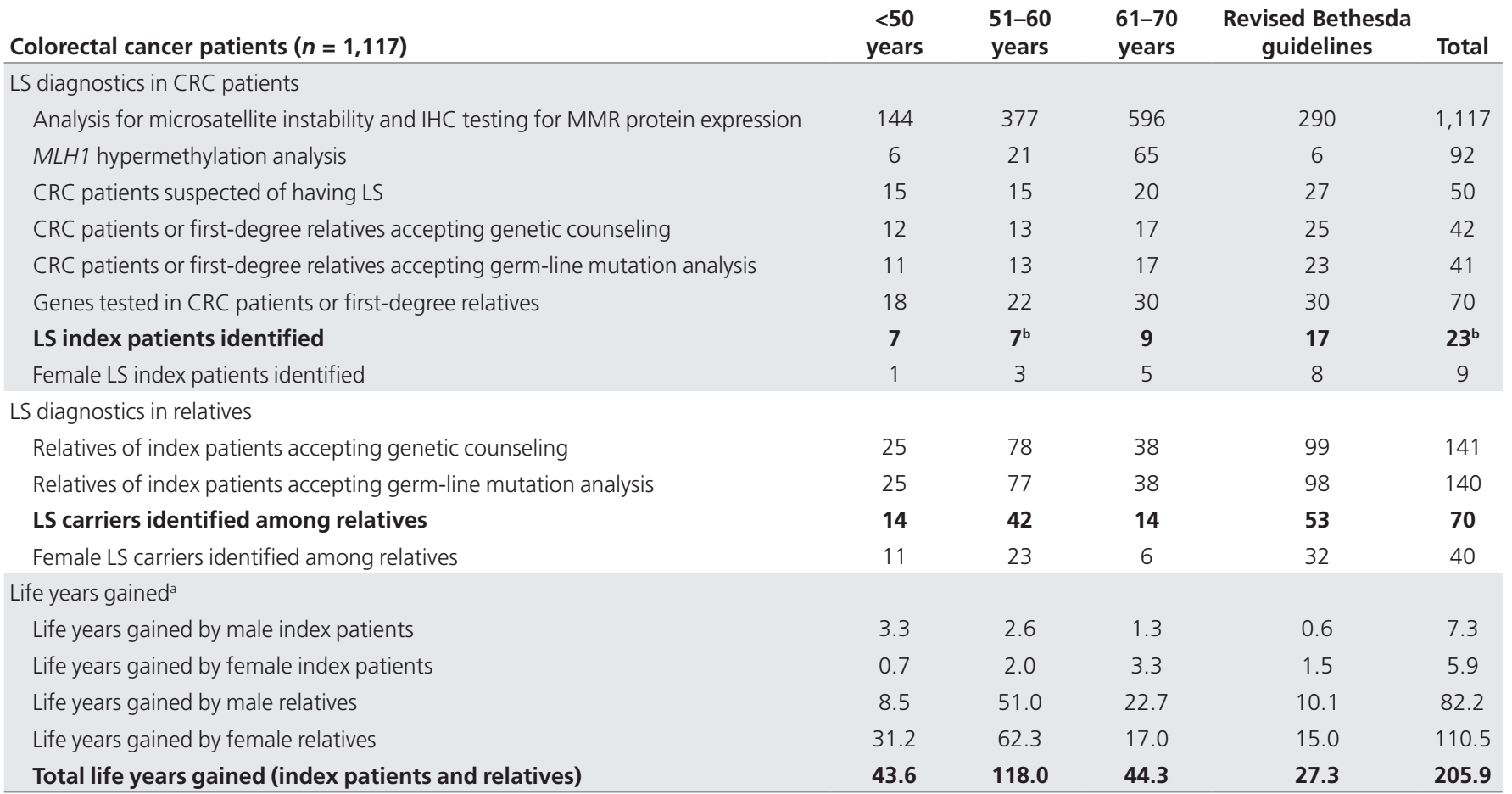

CRC, colorectal cancer; LS, Lynch syndrome; IHC, Immunohistochemistry; MMR, mismatch repair.

aNumbers of life years gained may not add up due to rounding. 'In one additional case, a germ-line mutation was identified in stromal tissue resected along with the CRC tissue. This patient was not considered an index patient because the patient and none of the relatives of that patient were available for germ-line mutation analysis. 
patient a median of 3 (interquartile range: $2-8$ ) relatives finally accepted counseling and germ-line targeted mutation analysis. A wide range-from 1 to 37 relatives-was tested for LS. In total, targeted mutation analysis was accepted by 140 relatives, identifying 70 additional LS carriers. Notably, more than three times as many LS carriers were identified among relatives of CRC patients 51-60 years of age as in the other age categories (Table 2). This difference was partly attributable to one index patient in the 51-60 age category with 37 relatives tested and 16 LS carriers identified.

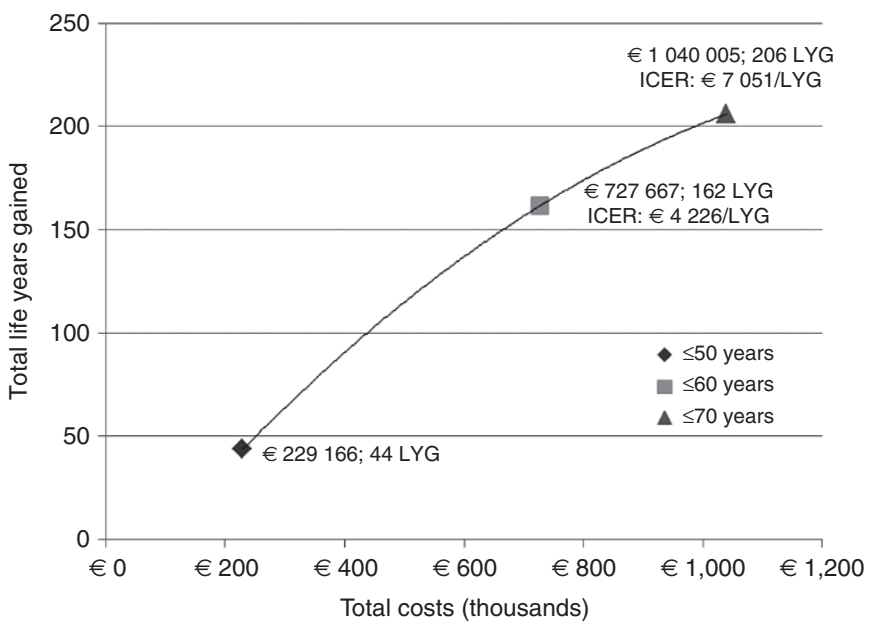

Figure 2 Total costs and life years gained (LYG) for Lynch syndrome screening in colorectal cancer patients $\leq 50$ years of age, $\leq 60$ years of age, and $\leq 70$ years of age. ICERs (incremental cost-effectiveness ratios) are expressed as incremental cost per additional LYG compared with the previous strategy.
Based on a median estimated benefit of LS surveillance of 0.66 years per index patient and 2.83 years per relative, a total of 205.9 life years were estimated to be gained by LS screening in CRC patients $\leq 70$ years of age. Surveillance of relatives led to the highest benefit, with a total of 192.7 LYG compared with a total of 13.2 LYG for index patients.

\section{Costs and cost-effectiveness}

Total costs of LS molecular screening and subsequent surveillance increased from $€ 229.166$ ( $€ 10.931$ per LS carrier detected) for CRC patients $\leq 50$ years of age to $€ 1.040 .005$ ( $€ 11.183$ per LS carrier detected) for CRC patients $\leq 70$ years of age (Figure 2 ).

LS screening for CRC patients $\leq 60$ years of age had an ICER of $€ 4.226 /$ LYG compared with screening patients $\leq 50$ years of age. The ICER of LS screening in CRC patients $\leq 70$ years of age compared with screening CRC patients $\leq 60$ years of age was $€ 7.051$ per LYG (Table 3).

In one-way sensitivity analysis, the ICERs were most sensitive to the assumed LYG by relatives (Supplementary Figure $\mathbf{S 1}$ online). The ICER for screening CRC patients $\leq 60$ years of age compared with screening patients with CRC diagnosed at $\leq 50$ years of age never exceeded $€ 8.000 / \mathrm{LYG}$. After exclusion of all family members of the largest family in our cohort (37 relatives, 16 LS carriers), this ICER remained less than $€ 10.000 / L Y G$. The ICER for screening CRC patients $\leq 70$ years of age compared with screening CRC patients $\leq 60$ years of age remained less than $€ 13.000 / \mathrm{LYG}$ under all assumptions (Supplementary Figure S1 online).

\section{Fulfillment of the revised Bethesda guidelines}

In our cohort, the revised Bethesda guidelines would have identified 17 of $23(74 \%)$ index patients and 53 of $70(76 \%)$

Table 3 Incremental costs in 2013 Euros for Lynch syndrome screening of CRC patients in different age categories

\begin{tabular}{|c|c|c|c|c|}
\hline CRC patients $(n=1,117)$ & $<50$ years & $51-60$ years & $61-70$ years & Total \\
\hline \multicolumn{5}{|l|}{ Lynch syndrome diagnostics } \\
\hline \multicolumn{5}{|l|}{ CRC patients } \\
\hline Molecular diagnostics & $€ 32,914$ & $€ 86,697$ & $€ 140,220$ & $€ 259,831$ \\
\hline Genetic counseling & $€ 3,574$ & $€ 3,872$ & $€ 5,064$ & $€ 12,510$ \\
\hline MMR gene sequencing & $€ 9,680$ & $€ 11,832$ & $€ 16,134$ & $€ 37,646$ \\
\hline \multicolumn{5}{|l|}{ Relatives } \\
\hline Genetic counseling & $€ 4,003$ & $€ 13,009$ & $€ 6,171$ & $€ 23,183$ \\
\hline Targeted mutation analysis & $€ 7,297$ & $€ 23,410$ & $€ 11,249$ & $€ 41,955$ \\
\hline \multicolumn{5}{|l|}{ Lynch syndrome surveillance } \\
\hline \multicolumn{5}{|l|}{ Colonoscopy surveillance } \\
\hline Index patients & $€ 27,929$ & $€ 19,924$ & $€ 12,358$ & $€ 60,211$ \\
\hline Relatives & $€ 61,226$ & $€ 174,933$ & $€ 61,226$ & $€ 297,385$ \\
\hline \multicolumn{5}{|c|}{ Gynecologic surveillance and prophylactic surgery } \\
\hline Index patients & $€ 5,754$ & $€ 24,263$ & $€ 25,634$ & $€ 55,651$ \\
\hline Relatives & $€ 91,970$ & $€ 183,939$ & $€ 49,465$ & $€ 325,374$ \\
\hline Savings by prevention of $C R C$ & $-€ 15,182$ & $-€ 43,378$ & $-€ 15,182$ & $-€ 73,743$ \\
\hline Total costs (minus savings) & $€ 229,166$ & $€ 498,501$ & $€ 312,338$ & $€ 1,040,005$ \\
\hline Total life years gained & 43.6 & 118.0 & 44.3 & 205.9 \\
\hline Costs per life year gained & Reference & $€ 4.226$ & $€ 7.051$ & - \\
\hline
\end{tabular}

CRC, colorectal cancer; MMR, mismatch repair. 
LS carriers among relatives, resulting in a total of 148.0 LYG. The total cost of this strategy amounted to $€ 662.123$, or $€ 9.459$ per LS patient detected. The ICER for routine LS screening in CRC patients $\leq 70$ years was $€ 7.341 /$ LYG compared with testing patients fulfilling the revised Bethesda guidelines. Excluding all 37 relatives from the large family in our cohort did not change this ICER because this family fulfilled the revised Bethesda guidelines. In the sensitivity analysis, this ICER did not exceed $€ 13.000 /$ LYG.

\section{DISCUSSION}

Our economic evaluation indicates that routine screening for LS in CRC patients $\leq 70$ years of age by analysis of MSI, IHC, and $\mathrm{MLH} 1$ hypermethylation is cost-effective according to currently accepted standards. In a one-way sensitivity analysis, expanding routine screening for LS from CRC patients $\leq 50$ years of age to CRC patients $\leq 60$ years of age never exceeded $€ 10.000 / \mathrm{LYG}$. Costs of LS screening among CRC patients 61-70 years of age were $€ 7.051 / L Y G$ in our base case analysis and remained less than $€ 13.000 / L Y G$ in one-way sensitivity analysis. The cost-effectiveness threshold of any diagnostic strategy depends on a health-care system's willingness to pay for each LYG. In the Dutch health-care system, willingness to pay depends on severity of the disease, and most interventions will be considered cost-effective if costs remain less than $€ 40.000 /$ LYG. $^{34}$ In the United Kingdom and the United States, a threshold of $\$ 50,000 / \mathrm{LYG}(\sim € 40,000 / \mathrm{LYG})$ is commonly used in cost-effectiveness analyses for cancer screening. However, thresholds over $\$ 50,000 /$ LYG can also be justified. ${ }^{35}$

Our sensitivity analysis confirmed the finding of other studies that the assumed benefit (LYG) from LS surveillance has a tremendous effect on ICERs, especially LYG assumed for relatives. ${ }^{12,16,17,23,24,27}$ The benefit of LS surveillance programs for relatives that we estimated from literature ranged from $0.40 \mathrm{LYG}$ to 16.74 LYG per relative (Table 1 and Supplementary Table S1 online). These extreme differences reflect the impact of assumptions made on uncertain parameters such as CRC risk for LS carriers, the method and risk reduction of LS surveillance, and assumed adherence to LS surveillance programs. In our base case analysis, we used the median of all estimations from the literature to attain plausible estimates. In our one-way sensitivity analyses, we considered the full range of estimates from the literature, which resulted in ICERs well within currently accepted thresholds for cost-effectiveness. Specifically, all ICERs remained less than $€ 13.000 / L Y G$.

LS screening in CRC patients $\leq 70$ years of age identified more than three times as many LS index patients compared with screening only CRC patients $\leq 50$ years of age. Also, LS carriers among family members of these index patients were identified. We found a median of three relatives who were tested for each index patient. However, there was a very wide range-from 1 to 37 - of relatives who were tested per index patient for a total of 140 relatives. Interestingly, in our study more than three times as many LS carriers were identified among relatives of CRC patients 51-60 years of age compared with the other age categories. This difference was partly caused by a very large family with 37 relatives tested and 16 LS carriers identified, which we may consider as a statistical outlier. Furthermore, the 51-60 age group contained 1.5 times as many first-degree relatives eligible for genetic testing compared with index patients $\leq 50$ years of age and had a higher prevalence of LS among tested relatives compared with the 61-70 years age category. Older age of siblings for CRC patients in the 61-70 years age category compared with siblings of younger CRC patients might explain this difference in LS prevalence because of the reduced life expectancy of LS carriers. Our study may still underestimate the number of LS patients ultimately detected among relatives. Relatives who do not undergo targeted mutation analysis as well as minors not yet eligible for genetic testing could request genetic testing at a later time. Also, CRC patients suspected of having LS who declined genetic testing might opt for MMR gene sequencing in the future, thereby further increasing the identification of LS carriers among CRC patients and their relatives. Further studies of these issues are necessary.

Our results are in line with previous studies using decision-analytic models, in which LS screening by only IHC testing or analysis for MSI for CRC patients $>50$ years of age was found to be cost-effective. ${ }^{16,17,26,27}$ In one study LS screening of CRC patients $\leq 60$ years of age led to an ICER of $\$ 33,800 / \mathrm{LYG}$ ( $€ 25,000 / \mathrm{LYG})$ compared with screening patients $\leq 50$ years of age. Expanding the age limit for LS screening to CRC patients $\leq 70$ years of age resulted in an ICER of $\$ 44,200 /$ LYG $(€ 33,000$ / LYG). ${ }^{16}$ By contrast, a recent Dutch study found an ICER of only $€ 2,703$ for LS screening in CRC patients $\leq 70$ years of age compared with LS screening of CRC patients $\leq 50$ years of age. ${ }^{26}$ However, this study did not include costs of gynecological surveillance. Furthermore, LYG for relatives in their study was 6.9 to 7.22 years, which is higher than assumed in other studies of cost-effectiveness of LS screening. Interestingly, the assumed incidence of CRC in LS carriers was higher than in other studies, which accounts for their high estimate of LYG per relative tested compared with other recent studies on cost-effectiveness of LS screening. Because we used the median of all estimates for LS benefit from the current literature, our ICERs are between those found by Sie et al. and those found by recent studies assuming benefit for LS carriers among relatives with less than 1 LYG.

Sensitivity of the revised Bethesda guidelines was 74\% in our cohort. In previous literature, the sensitivity of these guidelines was $72-88 \% .{ }^{19}$ To assess cost-effectiveness of age-targeted LS screening compared with the revised Bethesda guidelines, we assumed that only $26 \%$ of CRC patients in our cohort fulfilled the revised Bethesda guidelines. We assumed 100\% adherence to the revised Bethesda guidelines, whereas in clinical practice molecular diagnostics for LS may be performed in only 11$14 \%$ of the patients fulfilling these guidelines. ${ }^{11,36}$ In a previous study, low rates of failure to apply the revised Bethesda guidelines made LS screening by molecular diagnostics the preferred strategy. ${ }^{16}$ In our study, the ICER for LS screening among CRC patients $\leq 70$ years of age compared with testing according to 
the revised Bethesda guidelines remained less than €13.000/ LYG. Age-targeted LS screening may be much easier and therefore even more cost-effective to implement in clinical practice than clinical criteria based on family history.

LS screening without any age cutoff is presumed to further increase benefit for LS carriers. US guidelines recommended LS screening of all CRC patients by IHC or MSI analysis as a possible screening strategy. ${ }^{18}$ However, it is unclear whether the benefit of universal LS screening will come at acceptable costs. In our population-based cohort, the prevalence of LS decreased with increasing age of CRC diagnosis. Recently, universal tumor testing for LS was not found to be cost-effective by a model constructed by Barzi et al. ${ }^{22}$ Interestingly, the combination with predictive models was found to be cost-effective, but only in the case of available family history, which is known to be an important clinical challenge. In line with these findings, a German research group also concluded that the most cost-effective strategy involved family-history assessment. ${ }^{25} \mathrm{~A}$ recent international validation study confirmed the validity and potential clinical usefulness of prediction models to direct testing. ${ }^{37}$

Strengths of this study are the use of real-life data for index patients and their relatives, inclusion of MLH1 hypermethylation analysis in the diagnostic workup, our detailed analysis of diagnostic costs, and inclusion of gynecological surveillance. To our knowledge, this study is the first cost analysis for LS screening using cost data and family data derived directly from a prospective population-based cohort of CRC patients. In contrast to studies that rely fully on assumptions in cost-effectiveness models, we aimed to stay close to prospectively collected data. Furthermore, minimal cost savings by CRC prevention were used in the calculations. In practice, cost savings from LS screening are likely to be much higher.

This study also has several limitations. First, we did not correct LYG for quality of life. As posed by some, being identified as an LS carrier might not have an impact on quality of life, and it has been suggested that it is not necessary to include quality of life in cost-effectiveness analyses of lifesaving strategies. $^{38,39}$ However, two previous cost-effectiveness analyses of LS screening did find an impact on the ICER by including quality of life. ${ }^{17,40}$ Second, costs and benefit from surveillance for extracolonic cancers other than gynecological cancers were not included in our analyses because these are not generally recommended and the actual benefit of such surveillance is unclear. We also did not include costs of prophylactic colectomy or aspirin chemoprevention. Chemoprevention with aspirin in LS carriers has not yet been implemented because results of the CAPP3 study are pending. ${ }^{41}$ Third, we did not perform a full probabilistic sensitivity analysis. Furthermore, in this study we did not evaluate cost-effectiveness of MSI analysis and IHC alone. In previous studies, LS screening by IHC alone was found to be more cost-effective than LS screening by MSI analysis alone or MSI analysis and IHC combined. ${ }^{16,17}$ Finally, in this study we did not include the use of prediction models for LS detection because detailed family history was not available from all patients. MMRpro, MMRpredict, and PREMM ${ }_{1,2,6}$ have been proposed as prescreening tools for LS. ${ }^{42-44}$ It has been suggested that a combined strategy using IHC and prediction models among CRC patients $<70$ years of age improves the cost-effectiveness of LS detection. ${ }^{22,45}$ Prediction models may exclude CRC patients with a minimal risk of having LS from molecular diagnostics. Further research should therefore focus on validation of prediction models in population-based cohorts and evaluate the combination with molecular testing for LS.

In conclusion, routine screening for LS in CRC patients up to 70 years of age is a cost-effective strategy according to currently accepted standards, with important clinical benefits for LS carriers among CRC patients and their relatives. Our findings support the recent recommendation for LS screening by analysis of MSI or IHC and MLH1 hypermethylation in all CRC patients $\leq 70$ years of age. ${ }^{18,19}$

\section{SUPPLEMENTARY MATERIAL}

Supplementary material is linked to the online version of the paper at http://www.nature.com/gim

\section{ACKNOWLEDGMENTS}

This study was supported by Erasmus MC Translational Medicine. The sponsor did not play a role in the study design or the collection, analysis, or interpretation of data.

\section{DISCLOSURE}

The authors declare no conflict of interest.

\section{REFERENCES}

1. Green RC, Parfrey PS, Woods MO, Younghusband HB. Prediction of Lynch syndrome in consecutive patients with colorectal cancer. J Natl Cancer Inst 2009;101:331-340.

2. Matloff J, Lucas A, Polydorides AD, Itzkowitz SH. Molecular tumor testing for Lynch syndrome in patients with colorectal cancer. J Natl Compr Canc Netw 2013;11:1380-1385.

3. Moreira L, Balaguer F, Lindor N, et al.; EPICOLON Consortium. Identification of Lynch syndrome among patients with colorectal cancer. JAMA 2012;308: 1555-1565.

4. Lynch HT, de la Chapelle A. Hereditary colorectal cancer. N Engl J Med 2003;348:919-932.

5. Lynch HT, Lynch PM, Lanspa SJ, Snyder CL, Lynch JF, Boland CR. Review of the Lynch syndrome: history, molecular genetics, screening, differential diagnosis, and medicolegal ramifications. Clin Genet 2009;76:1-18.

6. Järvinen HJ, Aarnio M, Mustonen $\mathrm{H}$, et al. Controlled 15-year trial on screening for colorectal cancer in families with hereditary nonpolyposis colorectal cancer. Gastroenterology 2000;118:829-834.

7. Järvinen HJ, Renkonen-Sinisalo L, Aktán-Collán K, Peltomäki P, Aaltonen LA, Mecklin JP. Ten years after mutation testing for Lynch syndrome: cancer incidence and outcome in mutation-positive and mutation-negative family members. J Clin Oncol 2009;27:4793-4797.

8. Aaltonen LA, Salovaara R, Kristo P, et al. Incidence of hereditary nonpolyposis colorectal cancer and the feasibility of molecular screening for the disease. N Engl J Med 1998;338:1481-1487.

9. van Lier MG, Wagner $A$, van Leerdam ME, et al. A review on the molecular diagnostics of Lynch syndrome: a central role for the pathology laboratory. J Cell Mol Med 2010;14:181-197.

10. Umar A, Boland CR, Terdiman JP, et al. Revised Bethesda Guidelines for hereditary nonpolyposis colorectal cancer (Lynch syndrome) and microsatellite instability. J Natl Cancer Inst 2004;96:261-268.

11. Van Lier MG, De Wilt JH, Wagemakers JJ, et al. Underutilization of microsatellite instability analysis in colorectal cancer patients at high risk for Lynch syndrome. Scand J Gastroenterol 2009:44:600-604. 
12. Kievit W, de Bruin $\mathrm{JH}$, Adang EM, et al. Cost effectiveness of a new strategy to identify HNPCC patients. Gut 2005;54:97-102.

13. Hendriks $Y M$, Wagner $A$, Morreau $H$, et al. Cancer risk in hereditary nonpolyposis colorectal cancer due to MSH6 mutations: impact on counseling and surveillance. Gastroenterology 2004;127:17-25.

14. Senter $L$, Clendenning M, Sotamaa K, et al. The clinical phenotype of Lynch syndrome due to germ-line PMS2 mutations. Gastroenterology 2008;135: 419-428.

15. Gudgeon JM, Belnap TW, Williams JL, Williams MS. Impact of age cutoffs on a lynch syndrome screening program. J Oncol Pract 2013;9:175-179.

16. Ladabaum U, Wang G, Terdiman J, et al. Strategies to identify the Lynch syndrome among patients with colorectal cancer: a cost-effectiveness analysis. Ann Intern Med 2011;155:69-79.

17. Mvundura M, Grosse SD, Hampel H, Palomaki GE. The cost-effectiveness of genetic testing strategies for Lynch syndrome among newly diagnosed patients with colorectal cancer. Genet Med 2010;12:93-104.

18. Giardiello FM, Allen JI, Axilbund JE, et al.; US Multi-Society Task Force on Colorectal Cancer. Guidelines on genetic evaluation and management of Lynch syndrome: a consensus statement by the US Multi-Society Task Force on colorectal cancer. Gastroenterology 2014;147:502-526.

19. Vasen HF, Blanco I, Aktan-Collan K, et al.; Mallorca group. Revised guidelines for the clinical management of Lynch syndrome (HNPCC): recommendations by a group of European experts. Gut 2013;62:812-823.

20. van Lier MG, Leenen $\mathrm{CH}$, Wagner $\mathrm{A}$, et al.; LIMO Study Group. Yield of routine molecular analyses in colorectal cancer patients $\leq 70$ years to detect underlying Lynch syndrome. J Pathol 2012;226:764-774.

21. Dinjens WN, Dubbink HJ, Wagner A. Guidelines on genetic evaluation and management of Lynch syndrome. Gastrointest Endosc 2015;81:243-244.

22. Barzi A, Sadeghi S, Kattan MW, Meropol NJ. Comparative effectiveness of screening strategies for Lynch syndrome. J Natl Cancer Inst 2015;107.

23. Ramsey SD, Burke W, Clarke L. An economic viewpoint on alternative strategies for identifying persons with hereditary nonpolyposis colorectal cancer. Genet Med 2003;5:353-363.

24. Ramsey SD, Clarke L, Etzioni R, Higashi M, Berry K, Urban N. Cost-effectiveness of microsatellite instability screening as a method for detecting hereditary nonpolyposis colorectal cancer. Ann Intern Med 2001;135:577-588.

25. Severin F, Stollenwerk B, Holinski-Feder E, et al. Economic evaluation of genetic screening for Lynch syndrome in Germany. Genet Med 2016;17: 765-773.

26. Sie AS, Mensenkamp AR, Adang EM, Ligtenberg MJ, Hoogerbrugge N. Fourfold increased detection of Lynch syndrome by raising age limit for tumour genetic testing from 50 to 70 years is cost-effective. Ann Oncol 2014;25: 2001-2007.

27. Snowsill T, Huxley N, Hoyle M, et al. A systematic review and economic evaluation of diagnostic strategies for Lynch syndrome. Health Technol Assess 2014;18:1-406.

28. Syngal S, Weeks JC, Schrag D, Garber JE, Kuntz KM. Benefits of colonoscopic surveillance and prophylactic colectomy in patients with hereditary nonpolyposis colorectal cancer mutations. Ann Intern Med 1998;129: 787-796.

29. Vasen HF, van Ballegooijen M, Buskens E, et al. A cost-effectiveness analysis of colorectal screening of hereditary nonpolyposis colorectal carcinoma gene carriers. Cancer 1998;82:1632-1637.
30. Siegel JE, Weinstein MC, Russell LB, Gold MR. Recommendations for reporting cost-effectiveness analyses. Panel on Cost-Effectiveness in Health and Medicine. JAMA 1996;276:1339-1341.

31. Goede SL, van Roon AH, Reijerink JC, et al. Cost-effectiveness of one versus two sample faecal immunochemical testing for colorectal cancer screening. Gut 2013:62:727-734.

32. Organisation for Economic Co-operation and Development (OECD). Prices and Purchasing Power Parities. 2014. http://stats.oecd.org/. Accessed 1 April, 2015.

33. Lamberti C, Mangold E, Pagenstecher $C$, et al. Frequency of hereditary nonpolyposis colorectal cancer among unselected patients with colorectal cancer in Germany. Digestion 2006;74:58-67.

34. CVZ. Het pakketprincipe kosteneffectiviteit achtergrondstudie ten behoeve van de "appraisal" fase in pakketbeheer. College voor zorgverzekeringen: Diemen, The Netherlands, 2010.

35. Braithwaite RS, Meltzer DO, King JT Jr, Leslie D, Roberts MS. What does the value of modern medicine say about the $\$ 50,000$ per quality-adjusted life-year decision rule? Med Care 2008;46:349-356.

36. Cross DS, Rahm AK, Kauffman TL, et al.; CERGEN study team. Underutilization of Lynch syndrome screening in a multisite study of patients with colorectal cancer. Genet Med 2013;15:933-940.

37. Kastrinos F, Ojha RP, Leenen C, et al.; Lynch Syndrome prediction model validation study group. Comparison of prediction models for Lynch syndrome among individuals with colorectal cancer. J Natl Cancer Inst 2016;108.

38. Chapman RH, Berger M, Weinstein MC, Weeks JC, Goldie S, Neumann PJ. When does quality-adjusting life-years matter in cost-effectiveness analysis? Health Econ 2004;13:429-436.

39. Ramsey S, Blough D, McDermott C, et al. Will knowledge of gene-based colorectal cancer disease risk influence quality of life and screening behavior? Findings from a population-based study. Public Health Genomics 2010;13:1-12.

40. Wang G, Kuppermann M, Kim B, Phillips KA, Ladabaum U. Influence of patient preferences on the cost-effectiveness of screening for lynch syndrome. J Oncol Pract 2012;8(suppl 3):e24s-e30s.

41. Burn J, Mathers JC, Bishop DT. Chemoprevention in Lynch syndrome. Fam Cancer 2013;12:707-718.

42. Barnetson RA, Tenesa A, Farrington SM, et al. Identification and survival of carriers of mutations in DNA mismatch-repair genes in colon cancer. $N$ Engl J Med 2006;354:2751-2763

43. Chen S, Wang W, Lee S, et al.; Colon Cancer Family Registry. Prediction of germline mutations and cancer risk in the Lynch syndrome. JAMA 2006:296:1479-1487.

44. Kastrinos F, Steyerberg EW, Mercado R, et al. The PREMM $(1,2,6)$ model predicts risk of MLH1, MSH2, and MSH6 germline mutations based on cancer history. Gastroenterology 2011;140:73-81.

45. Kastrinos F, Steyerberg EW, Balmaña J, et al.; Colon Cancer Family Registry. Comparison of the clinical prediction model $\operatorname{PREMM}(1,2,6)$ and molecular testing for the systematic identification of Lynch syndrome in colorectal cancer. Gut 2013;62:272-279.

46. Vasen $H F$, Abdirahman $M$, Brohet $R$, et al. One to 2-year surveillance intervals reduce risk of colorectal cancer in families with Lynch syndrome. Gastroenterology 2010;138:2300-2306.

47. Koehler-Santos P, Izetti P, Abud J, et al. Identification of patients at-risk for Lynch syndrome in a hospital-based colorectal surgery clinic. World I Gastroenterol 2011:17:766-773. 